\title{
Pengembangan Multiplatform Game 2D Pengenalan Nama Benda Dalam Tiga Bahasa Untuk Anak Usia Dini
}

\author{
Emy Nurchasanah ${ }^{1 *}$, Endah Sudarmilah ${ }^{1}$ \\ ${ }^{1}$ Program Studi Informatika, Fakultas Komunikasi dan Informatika \\ Universitas Muhammadiyah Surakarta \\ *Emyhikarry@gmail.com, EndahSudarmilah@ums.ac.id
}

\begin{abstract}
ABSTRAK
Sudah banyak permainan dan aplikasi yang canggih dibandingkan beberapa tahun yang lalu. Setiap hari muncul jenis aplikasi baru, contohnya EduGame. Pada beberapa waktu yang lalu game pembelajaran sudah mulai banyak dikenal dengan berbagai variasi dan jenis. Di mulai untuk anak usia dini hingga sekolah menengah atas. Pada saat ini anak-anak usia dini lebih pandai dari pada anak-anak jaman dahulu. Dikarenakan pada masa saat ini teknologi sudah semakin maju dan lebih baik. Mereka dapat dengan mudah mengoprasikan alat elektronik seperti Tablet PC, Android dan Computer. Penelitian kali ini penulis ingin membuat Game pembelajaran bagi anak usia dini dalam pengenalan nama-nama benda dengan mengambil contoh buah, sayur dan hewan dalam tiga bahasa Indonesia-Inggris-Jepang agar mampu mengembangkan pengetahuan anak melalui game. Metode yang akan di gunakan adalah SDLC (System Development Life Cycle) dimana dalam merancang dan pembuatannya melalui tahap definisi kebutuhan, analisis, desain sistem, pembangunan, pengujian dan perawatan Penerapan game tersebut akan dapat di gunakan dalam Tablet PC, Android ataupun Computer. Berdasarkan penelitian yang dilakukan menurut 30 responden sebesar $97.3 \%$ aplikasi ini dapat menjadi media pembelajaran yang sesuai untuk anak usia dini dan $93.3 \%$ menyatakan aplikasi ini menarik untuk anak-anak
\end{abstract}

Kata kunci: Edugame, Pembelajaran, Bahasa, Android, komputer

\section{Pendahuluan}

Pendidikan saat ini semakin berkembang dari masa ke masa metode pendidikan juga mulai berubah dari metode pendidikan manual yakni belajar dari buku dan pengajar mulai meranah pada metode digital. Seperti halnya pengenalan nama buah dan sayur pada anak usia dini yang awalnya menggunakan papan kayu dengan gambar buah dan sayur serta hewan yang kemudian di perkenalkan oleh tenaga pendidik, tapi saat ini banyak metode baru yang digunakan untuk memperkenalkan anak pada berbagai macam hal melalui game dan juga media teknologi yang lebih menarik dan mudah di pahami oleh anak-anak.

Seperti halnya yang dikatakan Marc Prendky "Edugame adalah game yang didesain untuk belajar, tapi tetap bisa menawarkan bermain dan bersenangsenang. Edugame adalah gabungan dari konten edukasi, prinsip pembelajaran, dan game computer" dalam artikel Edugame menurut para ahli [7]. Sehingga perkembangan metode pembelajaran menggunakan game pun semakin meningkat dan banyak di cari oleh para orang tua untuk membantu pendidikan anak mereka.
Akan tetapi dalam pengaplikasian game tersebut terkadang menjadi kendala. Seperti halnya ketika aplikasi edugame tersebut hanya dapat di jalankan pada PC komputer saja atau hanya Tablet atau Android saja. Sehingga terkadang anak-anak menjadi bosan hanya memainkan itu saja. Oleh karena itu di butuhkan pengembangan multiplatform atau pengembangan aplikasi yang dapat dijalankan oleh beberapa media teknologi seperti game offline yang dapat dijalankan pada PC Komputer, tablet, dan Android. Dan game online yang dapat di akses mengunakan koneksi internet. Sehingga banyak variasi dalam memainkannya.

\section{A. Tinjauan Pustaka}

Menurut Dewi dalam Prihantoro dan Sudarmilah [5] dalam penelitiannya berjudul Pengembangan Game Edukasi Pengenalan Nama Hewan Dalam Bahasa Inggris Sebagai Media Pembelajaran Siswa SD Berbasis Macromedia Flash, sebagai model pembelajaran berupa permainan guna membantu daya tarik siswa dalam belajar. Tujuan peneliti dapat mempermudah siswa dalam menghafal dan menuliskan urutan huruf pada saat membentuk suatu kata dalam menyebutkan nama 
hewan, memudahkan guru dan siswa dalam mempelajari materi dikembangkanlah game edukasi animal pengenalan nama hewan dalam bahasa Inggris yang digunakan untuk siswa kelas IV dalam kegiatan pembelajaran di SD Negeri Somokaton. Game pembelajaran ini berbasis Macromedia Flash bertemakan "Pengenalan Nama Hewan Dalam Bahasa Inggris".

Menurut Rafidah [6] dalam penelitiannya yang berjudul "Perancangan Game Edukatif bersifat Farming dengan Tokoh Strawberry Shortcake" menyatakan bahwa edukasi merupakan proses prngrmbangan diri sebagai individu atau sosial dan ada berbagai cara dalam penerapannya untuk edukasi pada anak hendaknya menggunakan aspek bermain agar mereka lebih memahamibya. Dalam penelitiannya bertujuan membuat game edukasi bagi anak-anak yang dapat membantu mereka belajar mengenal buah, sayur dan hewan ternak, an mewarnai dalam pembuatan aplikasi ini peneliti menggunakan Macromedia Direct sebagai toolnya. Dan hasil dari aplikasi ini dapat berguna bag pembelajaran taman kanak-kanak.

Menurut Irfan [3] dalam peneliatian "Aplikasi game edukasi sebagai upaya untuk meningkatkan kemampuan berhitung pada anak berkebutuhan khusus Tuna Grahita" menyatakan bahwadapt memberikan dampak yang sangat positif bagi anak-anak dalam memahami materi pembelajaran. Sehingga tujuan peneliti membuat aplikasi ini agar dapat membantu anak-anak berkebutuhan khusu dalam meningkatkan kemampuat bejar mereka dalam berhitung dengan menggunakan Unity $3 D$ sebagau toolnya dan Kinect sebagai medianya. Dengan hasil bahwa aplikasi ini sedikit membantu anak berkebutuhan khusus dalam belajarnya dan dapat menghibur mereka dalam prosesnya.

Menurut Adiwijaya [1] dalam penelitiannya "Perencangan game edukasi Platform belajar matematika berbasis Android menggunakan Construct 2" Matematika merupakan studi atau pembelajaran pokok dan wajib bagi semua orang. Dan karenanya sangat di harapkan penerapannya di mulai dari anak usia dini karena di usia itulah anak-anak lebih mudah mengingat dan akan tertanam hingga dewasa. Sehingga peneli bertujuan membantu anak-anak dalam menerima pembelajaran berhitung melalui game platform yang mudah dan menyenangkan. Aplikasi ini dibuat menggunakan software Construct 2 berbasis android.

Berdasarkan penelitian terdahulu telah ada yang menjelaskan bahwa model pembelajaran berupa permainan atau game dapat meningkatkan daya tarik anak dalam belajar dan meningkatkan kemampuan anak dalam memahami materi pembelajaran. Aplikasi game ini melakukan pengembangan dengan aplikasi terdahulu yaitu Pengembangan Mutiplatform pengenalan nama benda dalam 3 bahasa untuk anak usia dini dengan menggunakan Construct 2 dimana construct merupakan software game engine yang terintegrasi untuk membuat game2D berbasis HTML5 yang mendukung berbagai platform seperti PC, iPhone, Mac, Android, IOS dan browser [9]. Tujuan dari penelitian ini adalah pembuatan model desain karakater dan obyek 2D yang digunakan untuk memberikan pengenalan nama pada anak dengan menggunakan bahasa Indonesia, Inggris dan Jepang. Pengenalan nama buah sayur serta hewan ini akan di sesuaikan dengan indikator pembelajaran untuk anak usia dini dengan tampilan yang tentunya dapat menarik minat anak dalam bermain dan belajar. Dalam pengenalan game tersebut akan di lakukan pada taman kanak anak yang mana terdapat tenaga pendidik anak usia dini yang mampu mengenali respon anak terhadap pembelajaran. Kemudian game tersebut di aplikasikan ke berbagai media teknologi.

\section{Metode}

Metode yang digunakan dalam penelitian ini adalah SDLC (System Development Life Cycle) merupakan metode yang mengambarkan pengembangan aplikasi dan sesuai dengan alur dari pembuatan aplikasi game ini. Tahapan yang dilakukan adalah definisi dan analisis kebutuhan yang akan di gunakan dalam penelitian yang tercantum pada alat dan bahan penetilian kemudian desain dan perancangan aplikasi melalui Storyline dan storyboard kemudian pembuatan aplikasi dan pengetesan aplikasi agar mengetahui hasil aplikasi tersebut berjalan dengan baik atau tidak.

\section{A. Alat dan Bahan}

Penelitian ini membutuhkan peralatan utama dan peralatan pendukung untuk perancang, membuat dan mengimplemetasikan game edukasi. Peralatan yang digunakan berupa hardware dan software sebagai berikut:

\section{Hardware}
a. $\quad$ Prosesor Intel $\AA$ core ${ }^{\mathrm{TM}_{\mathrm{i}}} \mathrm{3}-2328 \mathrm{M}$ with Intel $\mathbb{}$
b. HD graphics $3000 \mathrm{M}$
c. Hardisk $500 \mathrm{~GB}$
d. RAM 2 GB DDR3 Memory

\section{Software}
a. Construct 2221
b. CorelDraw X7
c. Free Audio Aditor
d. Nw.Js
e. Coconjs

\section{Bahan}

Bahan yang digunakan dalam Edugame pengenalan ini adalah Buah, Sayur dan Hewan serta 3 bahasa yang akan di gunakan ialah bahasa Indonesia-Inggris-Jepang. Dalam pembuatan aplikasi ini penulis melalukan survei internet serta buku untuk mengetahui nama-nama dari Buah, sayur dan hewan tersebut dalam bahasa Inggris dan Jepang. Nama-nama tersebut di ambil dari buku "Kamus Bahasa Indonesia-Jepang-Inggris" dan "Cara Mudah Mempelajari Bahasa Jepang". 
Untuk isi konten dalam game merupakan gambar 2 dimensi dari buah, sayur serta hewan beserta nama-namanya dari 3 bahasa Indonesia-Inggris dan Jepang yang mana setiap item di berikan audio untuk mempermudah anak dalam memahami materi yang di sajikan

\section{Obyek Penelitian}

Obyek yang menjadi penelitian dari aplikasi game ini adalah anak usia dini yang berada di Taman Kanak-kanak berusia antara 4 sampai 6 tahun.

\section{B. Perancangan Aplikasi}

\section{Gambar Flowchart Konsep game}

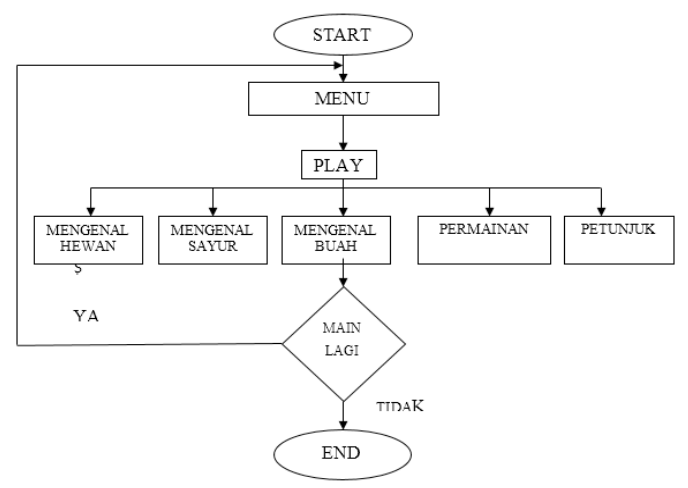

Gambar 1 Flowchart game

Gambar 1 menunjukan flowchart alur dari aplikasi game, yang mana di mulai dari halaman Menu yang terdapat 5 item Buah, Sayur, Hewan, Permainan dan Petunjuk. Untuk Buah, sayur dan Hewan menuju pada materi pengenalan. Setelah menyelesaikan materi dapat melakukan permainan. Kemudian user bisa melanjutkan aplikasi game atau menutup window untuk menyelesaikan game.

\section{Karakter}

Menggunakan karakter yang berfungsi untuk objek pendukung tampilan game dengan menggunakan Manju Tama yang merupakan animasi bola putih yang mana bisa tersenyum dan berkedip. Serta sebagai karakter tujuan anak untuk mendapatkan bintang.

\section{Storyline}

Storyline adalah alur yang menceritakan awal sebuah game dan tujuan akhir dari game tersebut. Dalam suatu game anak cenderung di berikan suatu Reward (Penghargaan) untuk menstimulasi anak agar lebih tertarik memainkan game tersebut [10] dan dalam aplikasi ini peneliti menggunakan bintang, score dan audio Exelent sebagai reward untuk anak. Dalam penelitian ini penulis menjelaskan bahwa pada tahap pertama user menggunakan aplikasi game tersebut akan di tujukan pada halaman Menu yang mana user dapat memilih icon Buah, Sayur, Hewan dan Petunjuk yang akan menjelaskan cara bermain. Untuk icon Permainan akan terkunci dan dapat di buka dengan cara user menyelesaikan salah satu materi Buah, Sayur atau Hewan. Sehingga user dapat mengaktikan icon permainan. Didalam icon permainan user di minta menyelesaikan 3 level dan membantu Tama yakni karakter dalam game untuk mendapatkan score dan bintang. Dan masingmasing level hanya bisa dilewati apabila user dapat menyelesaikannya satu persatu dimuai dari level 1.

\section{Storyboard}

Storyboard adalah rangkaian awal yang digambarkan penulis sebagai panduan untuk membuat aplikasi game sesuai dengan alur dan gambaran yang ditentukan. Ditunjukan pada Gambar 2 sampai Gambar 4 sebagai contoh.

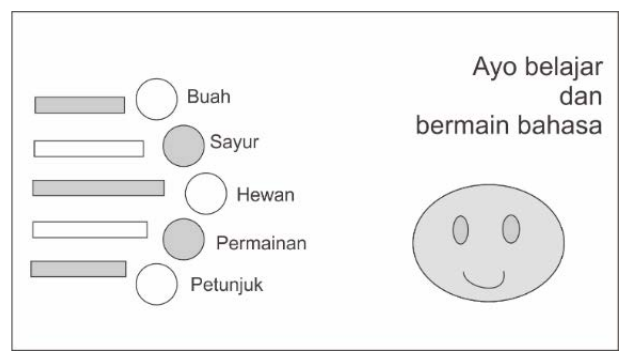

Gambar 2. Storyboard Halaman Menu

Gambar 2 adalah storyboard halaman menu atau halaman utama ketika aplikasi pertama kali dijalankan. User dapat memilih item sesuai keinginan dan akan masuk pada halaman selanjutnya..

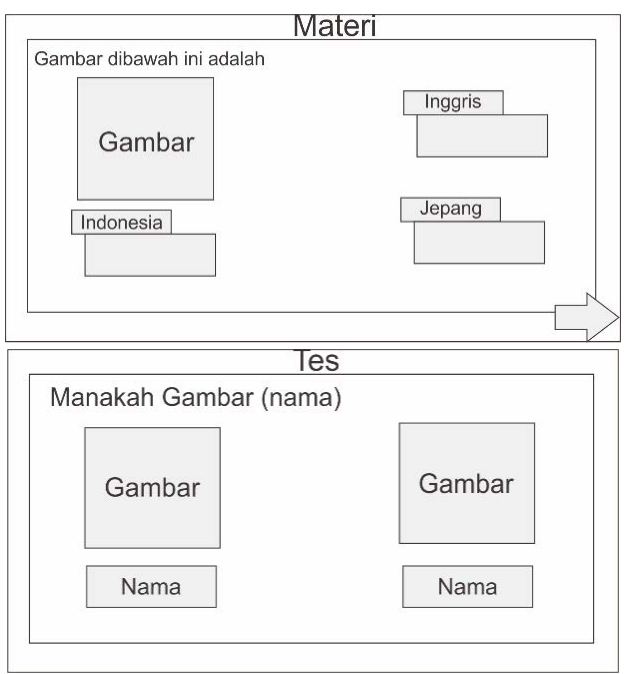

Gambar 3: Storyboard item Buah, Sayur dan Hewan

Gamber 3 adalah storyboard menu item yang digunakan pada materi buah, sayur dan hewan

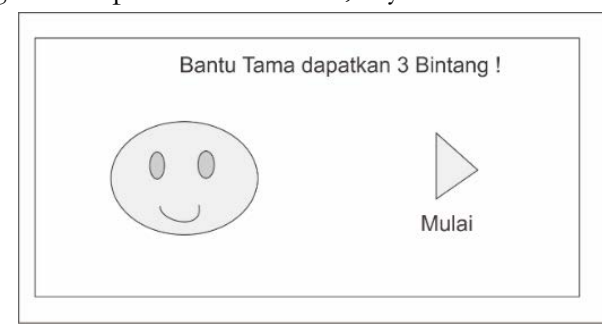




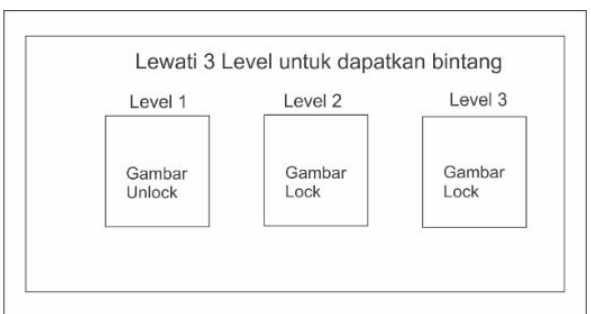

Gambar 4. Storyboard Permainan

Gambar 4 tampilan storyboard ketika user memilih menu Permainan yang akan aktif apabila menyelesaikan 1 item materi. User akan diminta untuk menyelesaikan 3 level untuk mendapatkan 3 bintang. Dan tiap level terkunci dan akan terbuka apabila user menyelesaikan level 1 dan seterusnya.

\section{Hasil}

Aplikasi edukasi Game untuk pengenalan nama benda ini dibuat menggunakan software Construct 2 v.221 dimana Construct 2 merupakan software yang terintegrasi untuk membuat game 2Dimensi berbasis HTML5, serta Construct 2 mendukung berbagai platform seperti PC, iPhone, Mac, Android, IOS dan browser [9]. Aplikasi ini tidak menggunakan bahasa pemrograman khusus, karena semua perintah yang digunakan pada game diatur dalam EvenSheet yang terdiri dari Event dan Action.

\section{A. Hasil Penelitian}

\section{Tampilan aplikasi}

Halaman aplikasi ini merupakan halaman utama ketika user membuka aplikasi. Gambar 5 di bawah ini merupakan tampilan dari halaman menu.

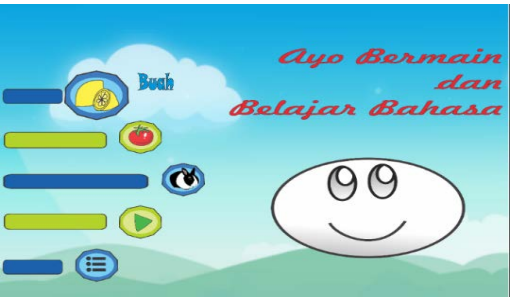

Gambar 5. Halaman Menu

Halaman menu terdiri dari item "Buah", "Sayur" dan "Hewan" yang mana merupakan tombol yang akan membawa user pada halaman materi dari masing-masing item. Kemudian ada tombol "Permainan" yang mana membawa user pada halaman game, sehingga user dapat bermain game yang berhubungan dengan materi. Dan "Petunjuk" sebagai halaman yang membantu user dalam menjalankan aplikasi game tersebut..

\section{Tampilan Item Buah, Sayur dan Hewan}

Halaman Materi Buah, Sayur dan Hewan memiliki desain yang sama seperti pada gambar 6 di bawah ini. Untuk masing-masing kategori materi terdapat 3 tahap materi. Materi 1 berisi 5 obyek, materi 2 bersi 7 obyek dan materi 3 berisi 10 obyek. Masing-masing materi juga memiliki tes untuk mengetahui hasil dari pembelajaran materi tersebut.
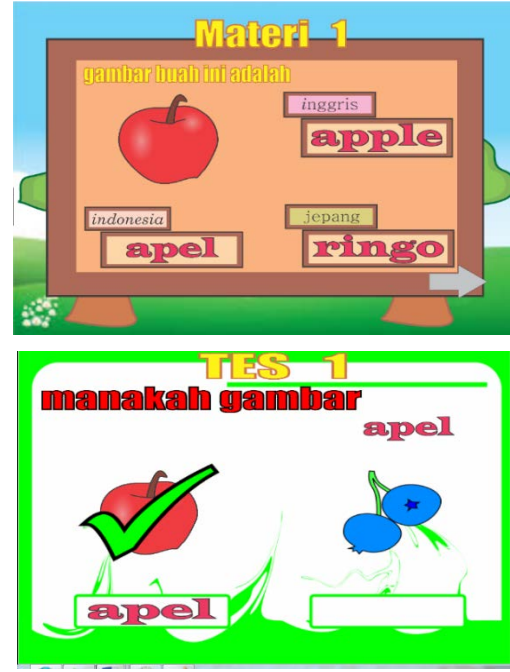

Gambar 6. Halaman Materi dan tes Buah, Sayur dan Hewan

\section{Halaman Permainan}

Halaman Permainan terdiri dari 3 Level yang memiliki kategori berbeda yang mana tiap level akan terkunci dan dapat di buka apabila menyelesaikan level awal, satu persatu untuk mendapatkan seore dan bintang.. Tampilan halaman Permainan pada gambar dibawah ini.
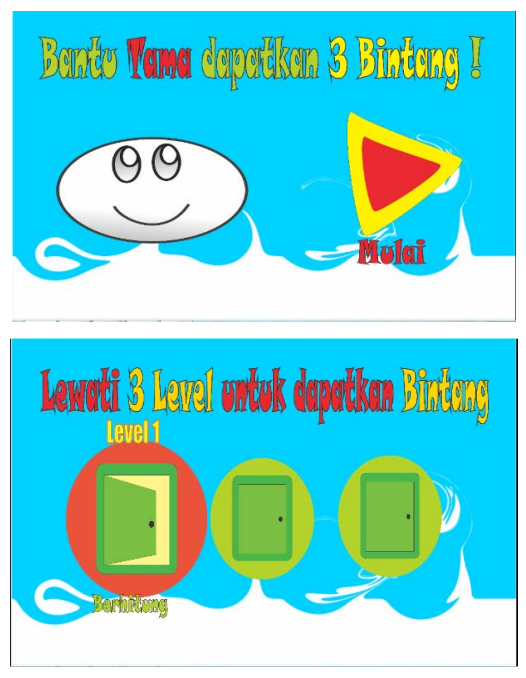

Gambar 7. Halaman Permainan

\section{Halaman Petunjuk}

Halaman petunjuk berisi tentang panduan untuk user dalam penggunaan aplikasi game ini. Halaman petunjuk ada pada gambar 8 di bawah ini.

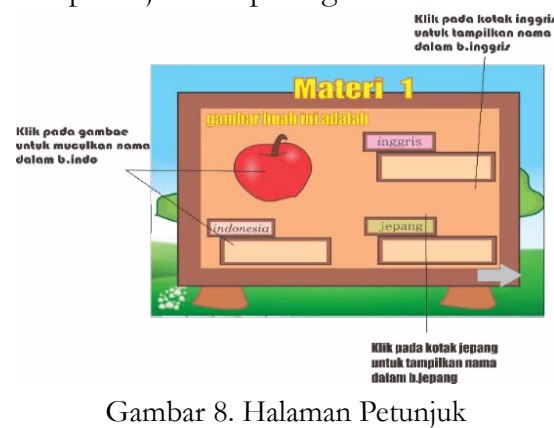

KHAZANAH INFORMATIKA | Online ISSN: 2477-698X 


\section{B. Analisa Penelitian}

1. Pengujian Blackbox

Aplikasi melakukan pengujian black box agar dapat mengetahui hasil akhir dari aplikasi tersebut.
Apakah berjalan dengan baik atau masih terdapat kendala, yang mana akan di perbaiki kembali sapai alikasi dapat berjalan dengan baik. Hasil pengujian black box dapat dilihal pada tabel 1 dan 2 di bawah ini.

Tabel 1 Pengujian Aplikasi

\begin{tabular}{|c|c|c|c|c|}
\hline NO & Data Masukan & Hasil yang diharapkan & Pengamatan & Kesimpulan \\
\hline 1. & Icon Buah & $\begin{array}{l}\text { Menampilkan halaman Materi } \\
\text { Buah }\end{array}$ & Menuju halaman materi buah & $\begin{array}{l}(\sqrt{ }) \text { Tampil } \\
(\quad) \text { Tidak }\end{array}$ \\
\hline 2 & Icon Sayur & $\begin{array}{l}\text { Menampilkan halaman Materi } \\
\text { Sayur }\end{array}$ & Menuju halaman materi sayur & $\begin{array}{l}(\sqrt{ }) \text { Tampil } \\
(\quad) \text { Tidak }\end{array}$ \\
\hline 3 & Icon Hewan & $\begin{array}{l}\text { Menampilkan halaman Materi } \\
\text { Hewan }\end{array}$ & Menuju halaman materi hewan & $\begin{array}{l}(\sqrt{ }) \text { Tampil } \\
(\quad) \text { Tidak }\end{array}$ \\
\hline 4 & $\begin{array}{l}\text { Gambar (Buah, } \\
\text { Sayur, Hewan) }\end{array}$ & $\begin{array}{l}\text { Menampilkan nama BSH dalam } \\
\text { b.indonesia }\end{array}$ & $\begin{array}{l}\text { Menampilkan nama BSH dalam } \\
\text { b.indonesia }\end{array}$ & $\begin{array}{l}(\sqrt{ }) \text { Tampil } \\
(\quad) \text { Tidak }\end{array}$ \\
\hline 5 & Kotak Inggris & Menampilkan nama b.inggris & $\begin{array}{l}\text { Menampilkan nama BSH dalam } \\
\text { b.inggris }\end{array}$ & $\begin{array}{l}(\sqrt{ }) \text { Tampil } \\
(\quad) \text { Tidak }\end{array}$ \\
\hline 6 & Kotak Jepang & Menampilkan nama b.jepang & $\begin{array}{l}\text { Menampilkan nama BSH dalam } \\
\text { b.jepang }\end{array}$ & $\begin{array}{l}(\sqrt{ }) \text { Tampil } \\
(\quad) \text { Tidak }\end{array}$ \\
\hline 7 & Tombol Next & $\begin{array}{l}\text { Menuju level atau materi } \\
\text { selanjutnya }\end{array}$ & $\begin{array}{l}\text { Menampilkan halam materi } \\
\text { selanjutnya }\end{array}$ & $\begin{array}{l}(\sqrt{ }) \text { Tampil } \\
(\quad) \text { Tidak }\end{array}$ \\
\hline 8 & Tombol Menu & Kembali ke halaman utama & $\begin{array}{l}\text { Kemballi menampilkan halaman } \\
\text { utama }\end{array}$ & $\begin{array}{l}(\sqrt{ }) \text { Tampil } \\
(\quad) \text { Tidak }\end{array}$ \\
\hline 9 & Icon Permainan & Menampilkan halaman game & $\begin{array}{l}\text { Membuka halaman game atau } \\
\text { permainan }\end{array}$ & $\begin{array}{l}(\sqrt{ }) \text { Tampil } \\
(\quad) \text { Tidak }\end{array}$ \\
\hline 10 & Icon Petunjuk & $\begin{array}{l}\text { Menampilkan petunjuk } \\
\text { permainan }\end{array}$ & $\begin{array}{l}\text { Menampilkan halaman petunjuk } \\
\text { permainan }\end{array}$ & $\begin{array}{l}(\sqrt{ }) \text { Tampil } \\
(\quad) \text { Tidak }\end{array}$ \\
\hline
\end{tabular}

Tabel 2 Pengujian Aplikasi pada media

\begin{tabular}{|c|c|c|c|c|}
\hline No & Nama Media & Spesifikasi & Hasil & Keterangan \\
\hline \multirow[t]{7}{*}{1.} & \multicolumn{4}{|l|}{ Android } \\
\hline & \multirow[t]{2}{*}{ Samsung Galaxy Star } & Android OS 4.1.2 (Jelly & ( ) Berjalan & \multirow[t]{2}{*}{ Aplikasi tidah berjalan dengan baik } \\
\hline & & Beans); RAM 1GB & $(\sqrt{ })$ Tidak & \\
\hline & \multirow[t]{2}{*}{ Sony Experia M2 } & \multirow{2}{*}{$\begin{array}{l}\text { Android OS 5.1.1 } \\
\text { (Lolipop); RAM 2GB }\end{array}$} & $(\sqrt{ })$ Berjalan & \multirow[t]{2}{*}{ Aplikasi berjalan baik } \\
\hline & & & ( ) Tidak & \\
\hline & \multirow{2}{*}{$\begin{array}{l}\text { Asus Zenfone } 2 \\
\text { Laser }\end{array}$} & \multirow{2}{*}{$\begin{array}{l}\text { Android } 6.0 \\
\text { (Marshmallow); RAM 2GB }\end{array}$} & $(\sqrt{ })$ Berjalan & \multirow[t]{2}{*}{ Aplikasi Berjalan baik } \\
\hline & & & ( ) Tidak & \\
\hline \multirow[t]{4}{*}{2.} & \multirow[t]{4}{*}{ Windows } & \multirow[t]{2}{*}{ Windows 7} & $(\sqrt{ })$ Berjalan & \multirow[t]{2}{*}{ Aplikasi berjalan baik } \\
\hline & & & ( ) Tidak & \\
\hline & & \multirow[t]{2}{*}{ Windows 8} & $(\sqrt{ })$ Berjalan & \multirow[t]{2}{*}{ Aplikasi berjalan baik } \\
\hline & & & ( ) Tidak & \\
\hline \multirow[t]{2}{*}{3.} & \multirow[t]{2}{*}{ HTML } & \multirow[t]{2}{*}{ HTML 5} & $(\sqrt{ })$ Berjalan & \multirow[t]{2}{*}{ Aplikasi berjalan baik } \\
\hline & & & ( ) Tidak & \\
\hline
\end{tabular}

Berdasakan hasil analisa yang dilakukan selama pembuatan dan uji coba aplikasi game pengenalan ini, dapat di ambil kesimpulan:

a. Aplikasi game ini dapat di jalankan pada Android dengan OS minimum Lolipop hingga Marshmalow yang mendukung webview. b. Aplikasi ini dapat berjalan dengan memory minimum 2GB dikarenakan game ini memerlukan memori 200-400 Mb. Apabila menggunakan RAM 1GB aplikasi dapat di tampilkan namun tidak akan berjalan dengan baik. 
c. Aplikasi game ini dapat dijalankan pada Laptop atau komputer yang memiliki OS windows 7 dan 8. Sebelum itu installasi aplikasi NW.JS (Node Webkit) terlebih dahulu sebagai mediatornya.

d. Aplikasi tersebut juga dapat langsung digunakan secara Online ataupun Offline menggunakan HTML 5.

e. Aplikasi game edukasi ini sudah mencakup proses pembuatan developer

\section{Pengujian Usabilitas}

Pengujian aplikasi dilakukan di RA Al Muayad Windan dan RA Al Mutaqin Makamhaji. Pengujian dilakukan kepada 18 anak Ra Al Muayad Windan dan 12 anak RA Al Mutaqin Makamhaji dengan total 30 anak yang telah mengisi kuisioner dibantu oleh tenaga pengajar dengan melihat respon dan hasil anak pada penggunaan aplikasi ini. Berikut merupakan hasilnya

Tabel Hasil Kuisioner Anak

Tabel 3 Tabel rekapitulasi hasil kuisioner anak

\begin{tabular}{|c|c|c|c|c|c|c|c|c|c|}
\hline \multirow{2}{*}{ No } & \multirow{2}{*}{ Nama } & \multicolumn{8}{|c|}{ Pertanyaan } \\
\hline & & P1 & $\mathbf{P 2}$ & P3 & $\mathbf{P 4}$ & P5 & P6 & P7 & P8 \\
\hline 1 & Malihatun Ni'mah & 4 & 4 & 5 & 5 & 5 & 5 & 5 & 5 \\
\hline 2 & Mauritsa Latifah A & 5 & 4 & 4 & 4 & 5 & 5 & 5 & 5 \\
\hline 3 & Fathna Alonis T & 5 & 5 & 5 & 5 & 4 & 5 & 5 & 5 \\
\hline 4 & Friska Safira Putra & 5 & 5 & 5 & 5 & 4 & 5 & 5 & 5 \\
\hline 5 & Anni Kusumawati & 5 & 5 & 5 & 5 & 3 & 4 & 5 & 4 \\
\hline 6 & Alena Khoirunnisa & 5 & 5 & 5 & 5 & 5 & 5 & 5 & 5 \\
\hline 7 & Lathifah Farah & 4 & 5 & 4 & 4 & 4 & 5 & 5 & 5 \\
\hline 8 & Cahaya Ramadhan & 5 & 5 & 5 & 5 & 5 & 5 & 5 & 5 \\
\hline 9 & Muhammad Imam & 5 & 5 & 5 & 5 & 4 & 5 & 4 & 5 \\
\hline 10 & M.Izaldin Z & 5 & 5 & 5 & 5 & 5 & 5 & 5 & 5 \\
\hline 11 & M. Fikri Azizi & 5 & 5 & 5 & 5 & 5 & 5 & 5 & 5 \\
\hline 12 & Maulana Tian P & 5 & 5 & 5 & 5 & 4 & 4 & 5 & 5 \\
\hline 13 & Arkan Ramadhan & 5 & 5 & 5 & 5 & 5 & 5 & 5 & 5 \\
\hline 14 & Fais Putra K & 5 & 5 & 5 & 5 & 4 & 5 & 5 & 5 \\
\hline 15 & Zahrom Ardhisa S & 5 & 5 & 5 & 5 & 4 & 4 & 4 & 5 \\
\hline 16 & Anaf Daffalaska S & 5 & 5 & 5 & 5 & 5 & 5 & 5 & 5 \\
\hline 17 & Syafi M. Isyaid & 5 & 5 & 5 & 5 & 5 & 5 & 5 & 5 \\
\hline 18 & Ahmad Husaid S & 5 & 5 & 5 & 5 & 4 & 4 & 4 & 5 \\
\hline 19 & Candraningrum $\mathrm{T}$ & 5 & 5 & 5 & 5 & 5 & 5 & 5 & 5 \\
\hline 20 & Ahmad Arsyad R & 5 & 5 & 5 & 5 & 5 & 5 & 5 & 5 \\
\hline 21 & Satria Ardhana P & 5 & 5 & 5 & 5 & 4 & 4 & 4 & 4 \\
\hline 22 & Azizah Zakia Suci & 5 & 5 & 5 & 5 & 5 & 4 & 4 & 5 \\
\hline 23 & Kinanti Mi A & 4 & 5 & 4 & 4 & 3 & 4 & 4 & 4 \\
\hline 24 & Kesya Alan P & 5 & 4 & 4 & 4 & 3 & 4 & 4 & 4 \\
\hline 25 & Anjelita Eliya L & 5 & 5 & 5 & 5 & 4 & 4 & 4 & 5 \\
\hline 26 & Berli Pragata P & 5 & 5 & 5 & 5 & 4 & 4 & 4 & 5 \\
\hline 27 & Faris naufal K & 5 & 5 & 5 & 5 & 4 & 5 & 5 & 5 \\
\hline 28 & Maida Asra Attri & 4 & 4 & 5 & 5 & 5 & 4 & 4 & 5 \\
\hline 29 & Galih Satria Utama & 5 & 5 & 5 & 5 & 5 & 5 & 5 & 5 \\
\hline 30 & Sheila Agnestia & 5 & 5 & 5 & 5 & 5 & 5 & 5 & 5 \\
\hline
\end{tabular}

Keterangan :

P1 : Tampilan Aplikasi "Pengembangan Multiplatform game 2D pengenalan nama benda dalam 3 bahasa untuk anak usia dini" ini menarik.

P2 : Tampilan gambar-gambar dan tulisan pada aplikasi game ini jelas

P3 : Audio pada aplikasi game ini jelas

P4 : Backsound pada aplikasi ini sesuai

P5 : Materi yang disajikan dalam aplikasi game ini mudah dipahami

P6 : Aplikasi game ini mudah digunakan

P7 : Materi yang diberikan sesuai dengan kemampuan anak usia dini

P8 : Aplikasi game ini membantu anak memahami nama-nama benda 
Menurut Sugiyono, Validitas merupakan derajad ketepatan antara data yang sesungguhnya terjadi pada obyek penelitian dengan data yang dapat dilaporkan oleh peneliti. Dengan demikian data yang valid adalah data "yang tidak berbeda" antara data yang dilaporkan oleh peneliti dengan data yang sesungguhnya terjadi pada obyek penlitian [2]. Jadi penelitian yang baik dan benar aoabila data komponen yang diteliti dinyatakan valid

Tabel 4 Nilai Korelasi

\begin{tabular}{l|cccccccc}
\hline \multicolumn{1}{l}{} & P1 & P2 & P3 & P4 & P5 & P6 & P7 & P8 \\
\hline Nilai korelasi & 0,458 & 0,413 & 0,685 & 0,685 & 0,756 & 0,714 & 0,663 & 0,730 \\
(r hitung) & Valid & Valid & Valid & Valid & Valid & Valid & Valid & Valid \\
\hline
\end{tabular}

Keterangan:

Item Kuisioner dikatankan valid jiaka $\mathrm{r}$ hitung $\geq$ daripada $\mathrm{r}$ tabel

Df $=\mathrm{n}-2$

Dalam data ini menggunakan $\mathrm{n}=30$, jadi nilai $\mathrm{df}=30-2=28$

Jadi untuk melihat tabel r ceri df 28 atau 30

Tabel $\mathrm{r}$ dari $\mathrm{df}=28=0.3610$

Skor ideal atau Skor Tertinggi $(\mathrm{SMax})=5 \mathrm{xn}=5 \mathrm{n}$ (SS)

Skor Terendah $($ SMin $)=1 \times n=n(S T S)$, dimana $n=$ total reponden

Skor $(\mathrm{S})=\sum$ (jumlah Responden Pemilih Jawaban $\mathrm{x}$ Bobot Jawaban)

Prosentase Interprestasi: $(\mathbf{P})=\operatorname{Skor}(\mathrm{S}) / \operatorname{Smax} \mathrm{x}$
$\mathbf{1 0 0} \%$

Pada penelitian untuk aplikasi ini jumlah Reponden sebesar 30 anak, oleh karena itu Skor Tertinggi $(\mathrm{Smax})=5 \times 30=150$.

Dengan demikian diperoleh hasil Prosentase Interprestasi (P) adalah:

Prosentase Interprestasi P1 : P = (146/150) x 100\% $=97,3 \%$

Prosentase Interprestasi P2 : P = (146/150) x 100\% $=97,3 \%$

Prosentase Interprestasi P3 : P $=(146 / 150) \times 100 \%$ $=97,3 \%$

Prosentase Interprestasi P4 : P = (146/150) x 100\% $=97,3 \%$
Prosentase Interprestasi P5 : P $=(132 / 150) \times 100 \%$ $=88 \%$

Prosentase Interprestasi P6 : P = (139/150) x 100\% $=92,7 \%$

Prosentase Interprestasi P7 : P = (140/150) x 100\% $=93,3 \%$

Prosentase Interprestasi P2 : P = (146/150) x 100\% $=97,3 \%$

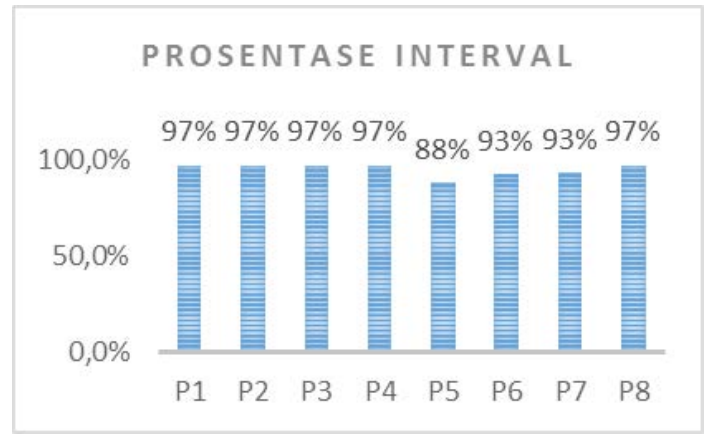

Gambar 9 Grafik hasil prosentase interva

Tabel 4 Tabel Skoring kuisioner anak

\begin{tabular}{|c|c|c|c|c|c|c|c|c|}
\hline \multirow{2}{*}{ NO } & \multirow{2}{*}{ Item } & \multicolumn{5}{|c|}{ Jumlah Jawaban } & \multirow{2}{*}{ Jumlah Score } & \multirow{2}{*}{$(\%)$} \\
\hline & & SS (5) & S (4) & $\mathbf{N}(3)$ & TS (2) & STS (1) & & \\
\hline 1 & P1 & 26 & 4 & 0 & 0 & 0 & 146 & $97,8 \%$ \\
\hline 2 & P2 & 26 & 4 & 0 & 0 & 0 & 146 & $97,8 \%$ \\
\hline 3 & P3 & 26 & 4 & 0 & 0 & 0 & 146 & $97,3 \%$ \\
\hline 4 & P4 & 26 & 4 & 0 & 0 & 0 & 146 & $97,3 \%$ \\
\hline 5 & P5 & 15 & 12 & 3 & 0 & 0 & 132 & $88 \%$ \\
\hline 6 & P6 & 19 & 11 & 0 & 0 & 0 & 139 & $92,7 \%$ \\
\hline 7 & P7 & 20 & 10 & 0 & 0 & 0 & 140 & $93,3 \%$ \\
\hline 8 & P8 & 26 & 4 & 0 & 0 & 0 & 146 & $97,3 \%$ \\
\hline
\end{tabular}




\section{Kesimpulan}

Berdasarkan penelitian yang telah dilakukan, kesimpulan yang dapat diambil diantaranya :

1) Aplikasi Pengembangan Multiplatform pengenalan nama benda dalam 3 bahasa untuk anak usia dini ini dapat di gunakan oleh tenaga pendidik atau orang tua sebagai sarana belajar anak-anak dalam mengenal Buah, Sayur dan Hewan dalam bahasa Indonesia-Inggris-Jepang.

2) Pengoperasian aplikasi bisa menggunakan PC komputer, Android serta dapat diakses melalui Browser.

\section{Daftar Pustaka}

[1] Adiwijaya, M., \& Christyono, Y. "Perancangan Game Edukasi Platform Belajar Matematika Berbasis Android Menggunakan Construct 2". TRANSIENT, 4(1), 2015. 128-133.

[2] Helianai. "Pengaruh Sistem Pengendalian Manajemen Terhadap Kinerja Manajerial Dengan Gaya Kepemimpinan Sebagai Variabel Moderating". Universitas Pendidikan Indonesia. Respository.upi. edu. 2012.

[3] Irfan, A. "Aplikasi Game Edukasi Sebagai Upaya Untuk Meningkatkan Kemampuan Berbitung Pada Anak Berkebutuhan Khusus Tuna Grabita” (Skripsi Universitas Muhammadiyah Surakarta). 2014.

[4] Jati Nugroho, S. "Aplikasi Pembelajaran Bahasa Inggris Untuk Anak SD Menggunakan Construct 2" (Skripsi Universitas Muhammadiyah Surakarta). 2015.

[5] Prihantoro, H. "Augmented Reality Edugame Daur Hidup Makbluk Hidup Berbasis Android” (Skripsi Universitas Muhammadiyah Surakarta). 2015
[6] Rafidah, Ismi" Perancangan Game Edukatif Bertema Farming Dengan Tokoh Strawberry Shortcake.". 2012. Skripsi, http://eprint.ums.ac.id/19182/ , 27 September 2015

[7] Rizal,'Edugame Menurut Para Ahli", artikel, http://segitiga.net/opinion/apa-itu-edugamemenurut-para-ahli , 25 September 2015

[8] Santi, I. T. "Pembuatan Game Pembelajaran Pengenalan Huruf Hijaiyah Di Taman KanakKanak (TK) Az-Zalfa Sidoharjo Pacitan”. SpeedSentra Penelitian Engineering dan Edukasi, 6(2). 2013. journal.ubaya.ac.id/index.php/ jimus/article/, 30 September 2015

[9] Sudarmilah, E., Ferdiana, R., Nugroho, L. E., Susanto, A., \& Ramdhani, N. (2013, October). Tech review: Game platform for upgrading counting ability on Preschool Children. In Prosiding on The 5th International Conference on Information Technology and Electrical Engineering (ICITEE 2013). 3 Mei 2016

[10] Sudarmilah, Endah, et al. "Developing a game for preschoolers: What character, emotion and reward will tend to hack preschoolers?." 2015 International Conference on Data and Software Engineering (ICoDSE). IEEE, 2015. 